\title{
Investigation of anger levels in adolescent individuals in terms of educational game variable
}

\author{
Mehibe AKANDERE \\ Faculty of Sport Science, Selcuk University, Konya, Turkey. \\ Address Correspondence to M. Akandere, e-mail; makandere@selcuk.edu.tr
}

\begin{abstract}
This study was carried out in order to investigate anger levels of adolescent students between 15 and 16 years old.The sample of the research constituted of 52 students (experiment group) who participated in physical education course and were applied 8-week educational play program regularly at the end of the course and other 52 students (control group) who participated in physical education course but were not applied educational play program. In order to determine anger levels of students, State-Trait Anger Scale developed by Spielberger was used. In dependent groups, paired $t$ test was applied while unpaired $t$ test was applied in independent groups. As a result, a significant difference was determined between pre-test and post-test values of Trait Anger, Anger Control, Anger Expression and Anger Suppression sub-dimensions of males and females participated in the research as experiment group. In control group, on the other hand, it was indicated that the scores of Anger Expression and Anger Suppression sub-dimensions of just females differed statistically and a significant difference was not found in Trait Anger and Anger Control sub-dimensions.
\end{abstract}

Keywords: Adolescent individual, anger control, educational play, exercise, school.

\section{INTRODUCTION}

Anger which has an important place among emotions varies in terms of intensity and continuity, emerges in relation with a sensation such as generally being exposed to an inaccurate behavior and is a situation of emotional rise and a negative feeling (28). Aggression is a multidimensional construct that develops within a complex interaction of biological, psychological, social, and cultural factors (31). Anger emerges when an individual encountered with preventions in daily life and aggression behavior emerges when anger cannot be controlled (5).

Törestad (27) determined that anger is not a situation which emerges by planning and mainly emerges in annoying situations such as inhibiton, being hard done, being criticized and being despised and on the other hand, Biaggio (9) determined that anger is a strong emotion of an individual aimed at putting away such annoying stimulants. Anger sometimes may be short-term, moderate and even beneficial to the person; sometimes may be very violent, intensive, trait and subversive. It was considered by Spielberger (24) that anger may be experienced with intensities varying from moderate sickness and excitation state to intense hostility and aggression state.

Dryden (13) presented that level of anger is generally directly proportional to self respect of the person and determined that people having low self respect are in tendency to be angry more easily than those having high self respect. In the researches of Edmonson \& Bullock (14) performed on primary school students and adolescents, findings revealing that adolescents display more angry and aggressive behaviors than primary school students were obtained. The child in adolescence period struggles in order to determine and be in control of one's own destiny and would like to be independent. For this reason, anger in adolescence period is intensely experienced in family.

Anger of adolescent is generally experienced sudden and sharp as burst of anger in the family (8). It is known that physical activity makes positive chages in respiratory, circulatory, skeletal and other organic systems. The people doing physical activity regularly were observed to give much faster neuralmuscular system reactions and have higher physical work capacity values as compared to sedentary people at the same age $(6,20)$. Children are always in 
growth and development process and in need of movement. The importance of movement development programs applied in this term is stressed by many researchers (15). An increase is observed in physical activity, physical development and social skills of children participating in sports organizations (29). Games played willingly and with pleasure, help the child's physical, emotional and social development. It is the most effective learning process for the child, and is thought to be necessary for the child's life. Game is an activity taking place in every term of life (11). In researches carried out, a parallel relation has been found between game and cognitive development (19).

Game has a property of being a main communication tool for childhood period (26). Game is a medium encouraged by revelation and inventions without preventing the the results (12). Playing games develop physical skills as well as language, mathematics and science skills (like comparing weights, distances and velocity), moreover encourage asking questions and discovery (16).

According to Winnicott (30), playing game includes confidence and is mainly satisfactory. This is true even when it causes anxiety at high levels. However, if anxiety occurs at a level that person cannot stand, this might suppress the game. Moreover, another property of playing game for a child is the liberation that he/she experienced in being creative during playing. The reason for a game to be important as much as this in terms of a child is that he/she is creative during playing.

In this regard, the importance of game and educational game concepts for the development of children stiffens more. The aim of this study is to investigate whether educational game program applied in physical education course has an effect on anger control level of students between 15 and 16 years old or not.

\section{MATERIAL \& METHOD}

The students participated voluntarily in this study which was performed to investigate whether educational game program applied in physical education course has an effect on anger control level of primary school students between 15 and 16 years old or not. The sample of the research constituted of 52 students (experiment group) who participated in physical education course and were applied 8-week educational game program regularly at the end of the course and other 52 students (control group) who participated in physical education course but were not applied educational game program. In order to determine anger levels of students participated in the research, State-Trait Anger Scale (STAS) developed by Spielberger (24) was used at the beginning of the research and at the end of 8 weeks.

\section{State-Trait Anger Expression Inventory (STAXI)}

The original STAXI provides a self-reported measure of the experience and expression of anger in 44 items (24). Although original version designed to measure anger as a situational emotional response (state) and as a predispositional quahty (trait), the Turkish version with 34 items that we used does not include state anger (17). Trait anger assesses the tendency to experience anger (i.e., anger proneness) so that higher scores indicate more frequent and intense anger. Individuals answered on a 4-point Likert scale (score range: 0-136). The STAXI also contains three scales designed to assess three different dimensions of the expression of anger: (a) Anger-In (anger suppression), (b) Anger-Qut (aggressive anger expression), and (c) AngerControl (inability to diminish the occurrence of angry feelings).

Educational game program applied in the research $(1,3)$ :

Educational Game 1. Get rid unite: Aim of the game; helping agility, reaction rate and development. Description of the game: The children are in a limited area disconnectedly. One of them is selected. He/she runs after others. Children suddenly join their hands not to be caught by him/her. He/she cannot catch the children who joined. $\mathrm{He} / \mathrm{she}$ tries to catch the ones who are single. The one caught by him/her becomes he/she.

Educational Game 2. Snow Rain Game: Aim of the game; development of attention and decision. Description of the game: A leader is selected. The leader stands in a place where he/she can see everyone in the classroom. To start the game, all children clap knees when "storm" is said. When "snow" is said, clap hands on chestand when "rain" is said, clap hands above. The leader says these words several times. Then leader says them by changing these words to amaze the children. The children who are amazed get out the game and the last one is applauded. The leader repeats the game and sees what the players do. This game develops attention. 
Educational Game 3. Handkerchief puss: Aim of the game; development of attention, agility and decision for players. Description of the game: The children are grouped into two. They stand behind straight line drawn 6-8 $\mathrm{m}$ away from each other in playground. They start counting from both left and right sides and every child has a number. The child in the middle of two groups has a handkerchief in the hand. This child says a number and the child with this number runs, comes to the middle and tries to catch the handkerchief and runs to his/her own place without being caught by other one. The group of this child who succeeded gains a grade. If he/she is caught, then opposing team gains a grade and the game goes on.

Educational Game 4. Rotating rope splash: Aim of the game; development of attention and tracking properties. Description of the game: The players are placed shoulder to shoulder orderly in the circle. The player in the middle has a rope in his/her hand which has alength of radius of the circle. A small weight is connected to the end of the rope. Rubber shoes, sandbag, etc. The player in the middle turns around him/herself and tried to touch the rope to the feet of players on the circle. The height of rope from the floor is $20-30 \mathrm{~cm}$. The players bounce on time to provide passing of rope under their feet. When the rope touches to feet of someone, then he/she changes the place with that of the player in the middle.

Educational Game 5. Seasons game: Aim of the game; development of agility and decision of players. Description of the game: The players are grouped into four seasons as "spring" "summer" "fall" and "winter". Each group goes to one corner determined, selects a player and sends them in the middle. The duty of these selected players is to hit the players in other groups and to join them in their own groups. When the teacher says spring and winter, the players of these two groups try to go opposite corners without being hit. While changing the corners, the players hit gain (-) numbers. The groups having the least (-) numbers become 1-2-3-4 respectively or the players hit become the member of the group whose player hit them, the group who gain more players wins the game. The teacher says "winter-fall"; "summer-spring" at the same time and sets two groups in motion.

Educational Game 6. Red-White: Aim of the game; helping development of agility, attention and auditory perception. Description of the game: The children are grouped into two equally. They sit behind the line drawn in the middle of playground back to back and being $1 \mathrm{~m}$ away from each other. One group is named as "red" the other is named as "white". When the teacher says the name of the group first, then that group starts to escape, other group runs after, i.e. if the teacher says (White-red), white escapes and red runs after. The players who are caught get out the game. This game may be played by giving different starting positions for children (long sitting, weltering, etc.).

Educational Game 7. Popping balloons: Aim of the game; Helping development of reaction, auditory perception, movement rate. Description of the game: The children stand in the lounge disconnectedly. Every child has a blown ballon in the hand. When the teacher says "start", then children try to catch each other's balloon and puncture it. The child who has more unpunctured ballons wins the game.

Educational Game 8. Kicking the ball rolling: Aim of the game; Helping agility and development of right shot. Description of the game: The class is grouped into two equally. The groups stand side to side with 8-10 meter distance. There is a handball in their hands. The children in the middle line who stand opposite have football in their hands. When the teacher says "start", the player who has football rolls the ball rapidly to his/her friend in the opposite. The children having handballs try to kick football with this handball. The group which kicks football gains one point.

Warm-up Stage at the beginning of Educational game program: Free race, changing directions, streching the neck forward, backward and both sides, arm-circling forward, backward, stretching and flank circles in which back and waist muscles work, stretching movements in which leg muscles work.

Cooling stage at the end of Educational gane program: Breathing exercises, body stretching movements forward, backward and sideways, stretching and straining arm and leg muscles.

\section{Statistical Analysis}

All statistical analyses were conducted using the Statistical Package for the Social Sciences (SPSS for Windows; SPSS 16.0, Inc., Chicago, IL). Standard statistical methods were used for the calculation of frequency and percent. The Kolmogorov-Smirnov test was used to determine if dependent variables were normally distributed. The Levine test was used to determine if there was homogeneity of variance. 
Paired $\mathrm{t}$ tests and unpaired $\mathrm{t}$-tests were used to determine significant differences for each dependent variable. For all analyses, the criterion for significance was set at an alpha level of $\mathrm{p}<0.05$

\section{RESULTS}

As it can be seen in Table 1, the mean value of trait anger in control group who do not do physical exercises regularly did not change in the research. However, pre-test mean of trait anger for individuals doing exercises (experiment group) was $26.31 \pm 4.55$ while its post-test mean value decreased to $19.19 \pm 3.49$. It was found that trait anger level of the group doing educational game exercise which was high at the beginning of exercise decreased at the end of the exercise.

When anger control value was investigated, pre-test mean value of control group was found as $11.78 \pm 3.04$ and post-test mean value was found as $11.96 \pm 2.40$ and no significant difference was observed between mean values. While pre-test value of anger control in experiment group was $13.50 \pm$ 3.26 , the mean value decreased to $9.94 \pm 2.10$ at the end of the exercise.
When anger expression sub-dimension values of individuals participated in the research was investigated, pre-test mean value of control group was found as $14.47 \pm 4.20$ and post-test value was found as $13.12 \pm 3.50$. While anger expression pretest value of experiment group was $14.96 \pm 3.70$, it decreased to $11.44 \pm 2.29$ at the end of educational game exercise.

When anger suppression sub-dimension values of individuals participated in the research was investigated, pre-test and post-test values of control group were found as $20.10 \pm 4.85$ and $21.71 \pm 3.45$, respectively. While anger suppression pre-test value of experiment group was $21.02 \pm 4.06$, it decreased to $17.10 \pm 2.98$ at the end of educational game exercise.

As it can be seen in Table 2, a significant difference was not determined between pre-test values of females when experiment and control groups were compared $(p>0.05)$. For males, on the other hand, while trait anger and anger control subdimensions were significantly different $(p<0.05)$, a significant difference was not found between anger expression and anger suppression values $(\mathrm{p}>0.05)$.

Table 1. Investigation of mean and standard deviation values of trait anger, anger control, anger expression and anger suppression sub-dimensions belonging to the subjects participated in the research

\begin{tabular}{|c|c|c|c|c|c|c|c|}
\hline \multirow{2}{*}{ Sub-dimensions } & & \multirow{2}{*}{ Gender } & \multirow{2}{*}{$\mathrm{N}$} & \multicolumn{2}{|c|}{ Experiment Group } & \multicolumn{2}{|c|}{ Control Group } \\
\hline & & & & Mean & Std. Deviation & Mean & Std. Deviation \\
\hline \multirow[t]{6}{*}{ Trait Anger } & Pre-test & Female & 26 & 24.38 & 4.53 & 23.58 & 5.11 \\
\hline & & Male & 26 & 28.23 & 3.76 & 25.56 & 5.22 \\
\hline & & Total & 52 & 26.31 & 4.55 & 24.59 & 5.21 \\
\hline & Post-test & Female & 26 & 19.08 & 2.97 & 23.25 & 3.95 \\
\hline & & Male & 26 & 19.31 & 4.00 & 25.24 & 4.12 \\
\hline & & Total & 52 & 19.19 & 3.49 & 24.27 & 4.12 \\
\hline \multirow[t]{6}{*}{ Anger Control } & Pre-test & Female & 26 & 12.54 & 3.54 & 11.96 & 2.80 \\
\hline & & Male & 26 & 14.46 & 2.70 & 11.60 & 3.29 \\
\hline & & Total & 52 & 13.50 & 3.26 & 11.78 & 3.04 \\
\hline & Post-test & Female & 26 & 9.54 & 2.30 & 11.50 & 2.55 \\
\hline & & Male & 26 & 10.35 & 1.83 & 12.40 & 2.20 \\
\hline & & Total & 52 & 9.94 & 2.10 & 11.96 & 2.40 \\
\hline \multirow[t]{6}{*}{ Anger expression } & Pre-test & Female & 26 & 13.81 & 3.76 & 14.79 & 3.93 \\
\hline & & Male & 26 & 16.12 & 3.33 & 14.16 & 4.51 \\
\hline & & Total & 52 & 14.96 & 3.70 & 14.47 & 4.20 \\
\hline & Post-test & Female & 26 & 10.96 & 2.41 & 13.38 & 3.55 \\
\hline & & Male & 26 & 11.92 & 2.10 & 12.88 & 3.50 \\
\hline & & Total & 52 & 11.44 & 2.29 & 13.12 & 3.50 \\
\hline \multirow[t]{6}{*}{ Anger suppression } & Pre-test & Female & 26 & 22.38 & 4.29 & 19.79 & 5.32 \\
\hline & & Male & 26 & 19.65 & 3.37 & 20.40 & 4.44 \\
\hline & & Total & 52 & 21.02 & 4.06 & 20.10 & 4.85 \\
\hline & Post-test & Female & 26 & 17.31 & 2.63 & 22.21 & 3.26 \\
\hline & & Male & 26 & 16.88 & 3.33 & 21.24 & 3.62 \\
\hline & & Total & 52 & 17.10 & 2.98 & 21.71 & 3.45 \\
\hline
\end{tabular}


Table 2. Comparison of pre-test values of trait anger, anger control, anger expression and anger suppression sub-dimensions belonging to the subjects participated in the research in terms of gender.

\begin{tabular}{|c|c|c|c|c|c|}
\hline \multirow{2}{*}{ Gender } & \multirow{2}{*}{ Pre-test } & \multicolumn{2}{|c|}{ Levene's Test } & \multirow{2}{*}{$\mathrm{t}$} & \multirow[b]{2}{*}{$\mathrm{p}$} \\
\hline & & $\mathrm{F}$ & $\mathrm{p}$ & & \\
\hline \multirow[t]{4}{*}{ Female } & Trait anger & .462 & .500 & .588 & .559 \\
\hline & Anger control & 1.898 & .175 & .639 & .526 \\
\hline & Anger expression & .021 & .885 & -.904 & .371 \\
\hline & Anger suppression & 1.280 & .264 & 1.903 & .063 \\
\hline \multirow{4}{*}{ Male } & Trait anger & 3.023 & .088 & 2.103 & $.041^{*}$ \\
\hline & Anger control & 1.322 & .256 & 3.400 & $.001^{*}$ \\
\hline & Anger expression & 1.448 & .235 & 1.768 & .083 \\
\hline & Anger suppression & 1.538 & .221 & -.677 & .501 \\
\hline
\end{tabular}

$\mathrm{P}<0.05$

Table 3. Comparison of post-test values of trait anger, anger control, anger expression and anger suppression sub-dimensions belonging to the subjects participated in the research in terms of gender.

\begin{tabular}{|c|c|c|c|c|c|}
\hline \multirow{2}{*}{ Gender } & \multirow{2}{*}{ Post-test } & \multicolumn{2}{|c|}{ Levene's Test } & \multirow{2}{*}{$\mathrm{t}$} & \multirow[b]{2}{*}{$\mathrm{p}$} \\
\hline & & $\mathrm{F}$ & $\mathrm{p}$ & & \\
\hline \multirow{4}{*}{ Female } & Trait anger & 2.755 & .103 & -4.247 & $.000^{*}$ \\
\hline & Anger control & .003 & .957 & -2.857 & $.006^{*}$ \\
\hline & Anger expression & 2.964 & .092 & -2.834 & $.007^{*}$ \\
\hline & Anger suppression & 1.176 & .284 & -5.870 & $.000^{*}$ \\
\hline \multirow{4}{*}{ Male } & Trait anger & .073 & .788 & -5.222 & $.000^{*}$ \\
\hline & Anger control & .871 & .355 & -3.630 & $.001^{*}$ \\
\hline & Anger expression & 2.693 & .107 & -1.189 & .240 \\
\hline & Anger suppression & .240 & .626 & -4.476 & $.000^{*}$ \\
\hline
\end{tabular}

$\mathrm{P}<0.05$

Table 4. Comparison of pre-test and post-test values of trait anger, anger control, anger expression and anger suppression sub-dimensions belonging to the subjects of experiment and control groups participated in the research.

\begin{tabular}{|c|c|c|c|c|c|}
\hline \multirow{2}{*}{ Variables } & & \multicolumn{2}{|c|}{ Female } & \multicolumn{2}{|c|}{ Male } \\
\hline & & $\mathrm{t}$ & $\mathrm{p}$ & $\mathrm{t}$ & $\mathrm{p}$ \\
\hline \multirow[t]{2}{*}{ Trait anger } & Experiment & 6.455 & $.000^{*}$ & 9.921 & $.000^{*}$ \\
\hline & Control & .394 & .697 & .419 & .679 \\
\hline \multirow[t]{2}{*}{ Anger control } & Experiment & 3.598 & $.001^{*}$ & 6.939 & $.000^{*}$ \\
\hline & Control & 1.027 & .315 & -1.225 & .233 \\
\hline \multirow[t]{2}{*}{ Anger expression } & Experiment & 4.180 & $.000^{*}$ & 6.870 & $.000^{*}$ \\
\hline & Control & 2.089 & $.048^{*}$ & 1.216 & .236 \\
\hline \multirow[t]{2}{*}{ Anger suppression } & Experiment & 5.813 & $.000^{*}$ & 3.968 & $.001^{*}$ \\
\hline & Control & -2.168 & $.041^{*}$ & -1.293 & .208 \\
\hline
\end{tabular}

$\mathrm{P}<0.05$

As it can be seen in Table 3, when post-test values of experiment and control groups were compared, a difference was determined in all subdimensions for females $(p<0.05)$. While a significant difference was found in trait anger, anger control and anger suppression sub-dimensions for males $(\mathrm{p}<0.05)$, a significant difference was not determined between experiment and control groups in just anger expression sub-dimension ( $p>0.05)$.

When Table 4 is investigated, it was determined that pre-test and post-test values of Trait anger, Anger control, Anger expression and Anger suppression sub-dimensions belonging to females and males in experiment group were significantly different $(p<0.05)$. In control group, on the other hand, the values of anger expression and anger suppression belonging to just females differed significantly $(\mathrm{p}<0.05)$ and a significant difference was not found between trait anger and anger control sub-dimensions ( $\mathrm{p}>0.05)$.

\section{DISCUSSION}

In this study, when anger levels of children between 15 and 16 years old depending on educational game exercise were investigated, the following results were obtained: The mean value of trait anger in control group who do not do physical exercises regularly did not change in the research. 
However, it was determined that pre-test mean of trait anger for individuals doing exercises (experiment group) was $26.31 \pm 4.55$ while its posttest mean value decreased to $19.19 \pm 3.49$ (Table 1). It was found that trait anger level of the group doing educational game exercise which was high at the beginning of exercise decreased at the end of the exercise. The high grades of trait anger indicated that the anger level was also high (23).

When anger control sub-dimension was investigated, pre-test mean value of control group was found as $11.78 \pm 3.04$ and post-test mean value was found as $11.96 \pm 2.40$ and no significant difference was observed between mean values. While pre-test value of anger control in experiment group was $13.50 \pm 3.26$, the mean value decreased to $9.94 \pm 2.10$ at the end of the exercise. High grades of anger control sub-dimension indicated that anger can be controlled. In this regard, it was observed that the anger control level of the group doing educational game exercise decreased at the end of exercise.

As a result of a research, it was revealed that avoidance in overcoming the stress explains anger expression behavior significantly. Moreover, it was found that there is a negative significant relationship between overcoming the stress and anger expression while there is a positive significant relationship between overcoming the stress and anger control. This result indicated that as avoidance behaviors of students in overcoming the stress increase, their anger expression behaviors decrease and anger control behaviors (4).

Suppression of anger revealed that the anger felt by the individual is suppressed and not expressed; expression of anger revealed that anger is represented and control of anger revealed that the effort for controlling of anger $(25,23,17)$.

Trait anger is defined as perception of many situations or environments as boring or preventive and depending on this, having a tendency of experiencing situational anger more frequently. Suppression of anger revealed that the anger felt by the individual is suppressed and not expressed; control of anger revealed the effort for controlling of anger and expression of anger revealed that anger is represented $(17,25,23)$.

When anger expression sub-dimension values belonging to individuals of control group participated in the research were investigated, pretest mean value was found as $14.47 \pm 4.20$ and post- test value was found as $13.12 \pm 3.50$. While anger expression mean values of experiment group were investigated, it was determined that pre-test was $14.96 \pm 3.70$ and it decreased to $11.44 \pm 2.29$ at the end of educational game exercise. The decrease in the mean value of experiment group at the end of the exercise indicated that anger expression can be controlled and there was a positive relationship between exercise and anger expression (Table 1).

In a study which was performed to investigate perceived impact of anger and anxiety on sporting performance in rugby players, findings of the present study provided some support for this position in as much as direction scores of Anger-in were lower than scores of Anger-out. Also, there was about the same number of athletes who reported either facilitative or debilitative effects of Anger-in (i.e., direction scores 40), whereas more participants perceived Anger-out as facilitative rather than debilitative. Support was provided for assessment of individual's interpretation of anger symptoms (21).

When anger suppression sub-dimension values belonging to individuals of control group participated in the research were investigated, pretest and post-test values of control group were found as $20.10 \pm 4.85$ and $21.71 \pm 3.45$, respectively. While anger suppression sub-dimension values of experiment group were investigated, pre-test value was $21.02 \pm 4.06$ and it decreased to $17.10 \pm 2.98$ at the end of educational game exercise. The decrease in the mean value of experiment group at the end of the exercise indicated that the level of anger suppression also decreased. In this regard, it was determined thateducational game exercise positively affected the individuals of experiment group in terms of suppressing anger suppression levels (Table 1).

In another study which was related with anger levels of adolescents, the mean anger scores of high school students were significantly higher than those of middle school students, and male students' anger scores were higher than those of female students. Anger, anger expression, and suicidal ideation exhibited significant differences according to school level and gender.The group with higher anger and anger expression showed a higher average suicidal ideation score than that of the group with lower anger and anger expression, suggesting that schoolbased programs which alleviate anger may be needed to decrease suicidal ideation among Korean adolescents (18). 
When experiment and control groups participated in the research were compared, a significant difference was not determined between pre-test values of females. For males, on the other hand, while it was determined that trait anger and anger control sub-dimensions were significantly different; a significant difference was not found between anger expression and anger suppression values. It was also determined that trait anger and anger control sub-dimensions of males in experiment and control groups were significantly different (Table 2). It was indicated that educational game exercise applied on experiment group had a positive effect on experiment group in terms of trait anger and anger control levels when compared to control group.

In a study which investigated depression levels of adolescents between 12 and 15 years old in terms of game variable, it was determined that depression symptoms of individuals having short daily duration of game were high and the game factor necessary for children affected their depression level (7). The findings of this study were in accordance with those of our study.

When post-test values of experiment and control groups were compared, a difference was determined in all sub-dimensions for females. While a significant difference was found in trait anger, anger control and anger suppression subdimensions for males, a significant difference was not determined between experiment and control groups in just anger expression sub-dimension. It was determined that educational game exercise applied on experiment group positively affected anger levels of females and had a positive development in trait anger, anger control and anger suppression sub-dimensions for males (Table 3).

In a study where anger and anxiety levels of male sportsmen in different branches of sports were investigated, it was determined that anger levels of sportsmen were moderate $(22.37 \pm 5.22)$. It was observed that sportsmen who can control anger had low levels of anxiety (10).

The study which was performed in order to investigate the effect of sports on aggression phenomenon and to investigate aggression levels of secondary school students who do physical exercises and do not do, a significant relationship was determined between aggression levels of students participated in the research and doing physical exercises. It was considered that orienting children for sports to have a healthy development as physically and mentally was important in terms of preventing negative impulsions such as depressive feelings, anger and aggression in children (2).

It was determined that pre-test and post-test values of Trait anger, Anger control, Anger expression and Anger suppression sub-dimensions belonging to females and males in experiment group were significantly different. In control group, on the other hand, the values of anger expression and anger suppression belonging to just females differed significantly and a significant difference was not found between trait anger and anger control subdimensions (Table 4).

In the study which was performed to investigate the profiles of anger control in secondgrade children, latent profile analysis (LPA) was used to examine anger control in 257 second-grade children (8 years of age). Anger was induced through losing a game and prize to a confederate who cheated. The findings of the study were discussed in terms of implications for the assessment of children's anger control skills and intervention programs for children's anger management (22). It was also determined in another study that attention levels of children between 9 and 13 years old who were applied educational game program for 8 weeks were positively developed (3). When the importance of game for children is taken into consideration, it can be concluded that game is an effective factor not only in the control of negative feelings such as anger but also in the development of many positive feelings. The findings of various studies related with games also support the findings of our study.

In the study which was performed to investigate the profiles of anger control in secondgrade children, latent profile analysis (LPA) was used to examine anger control in 257 second-grade children (8 years of age). Anger was induced through losing a game and prize to a confederate who cheated. The findings of the study were discussed in terms of implications for the assessment of children's anger control skills and intervention programs for children's anger management (22).

Consequently; it was determined that there was a significant difference between pre-test and posttest values of trait anger, anger control, anger expression and anger suppression sub-dimensions of experiment group. It was indicated that 
educational game exercises applied in Physical Education courses of students between 15 and 16year old positively affected their anger control. It can be concluded that the children playing educational games were more successful in anger control than the group not playing games.

\section{REFERENCES}

1. Akandere M. Eğitici Okul Oyunları, Nobel Yaynları, 2. Baskı, 2004, 34-102.

2. Akandere M, Yıldız S, Baştuğ G, Arslan F. The study of aggression level of secondery students who play sports and do not play sports. Ovidius University Annals, Series Physical Education and Sport, Science, Movement and Health, 2009: 9(2): 202.

3. Akandere $M$, Baştuğ $G$, Aşan R, Baştuğ $K$. The effect of educational game over attention in children. Ovidius University Annals, Series Physical Education and Sport, Science, Movement and Health, 2010; 10(2): 325.

4. Arslan C. Öfke ve öfkeyi ifade etme biçimlerinin, stresle başa çıkma ve kişiler arası problem çözme açısından incelenmesi Kuram ve Uygulamada Eğitim Bilimleri / Educational Sciences: Theory \& Practice, 2010; 10.

5. Averill JR. Studies on anger and aggression: implications for theories of emotion. American Psychologist, 1983; 38: 11451162.

6. Baker SJ, Jacques P, Maurrssen J, Chrzan GJ. Simple reaction time and movement time in normal human voluntaries : a long term reliable study. Perceptual and Motor Skill, 1991; 63 767-774.

7. Baştuğ G, Duman S, Özdağ S. Examining the depressive symptoms of 12-15 year-old Turkish adolescents according to play variable. World Applied Sciences Journal, 2011; 13(3): 615-622.

8. Bauman L, Riche R. The Ten Most Troublesome Teen-age Problems and How to Solve Them. Toronto, ON: Carol Publishing Group, 1997.

9. Biaggio MK. Sex differences in behavioral reactions to provocation of anger. Psychological Reports, 1989; 64: 23-26.

10. Birinci R, Sivrikaya AH, Erhan ES. Farklı Spor Branşlarındaki Erkek Sporcuların Öfke ve Anksiyete Düzeylerinin İncelenmesi, Turkiye Klinikleri J Sports Sci, 2012; 4(1): 16-21.

11. Carusa DA. Infants Exploratory Play: Implications for Child Cart. Young Children, 1984; 11: 27-30.

12. Daubrova DA. The Effects of Child-Centered Group Play Therapy on Emotional Intelligence, Behavior and Parenting Stress, Walden University, Dissertation Submitted in Partial Fulfilment of the Requirements fort he Degree of Doctor of Philosophy Clinical Psychology, 2005.

13. Dryden W. Dealing with Anger Problems: Rational-Emotive Therapeutic Interventions. Sarasota, FL: Professional Resources Exchange, 1990.

14. Edmonson H, Bullock L. Youth with aggressive and violent behaviors: pieces of a puzzle, Preventing School Failure, 1998, 42(3): 135-141.
15. Kahl H, Emmel J. The motor aktivity study segment as pilot study of the child and adolescent health survey, Gesundheitswesen 2002; 64(Suppl 1): S114-8.

16. Napier N, Sharkey A. Play. D. Wyse (Edt.), Childhood Studies. An Introduction Oxford: Blackwell Publishing, 2004.

17. Özer A. Sürekli öfke ve öfke ifade tarzı ölçekleri ön çalışması. Türk Psikoloji Dergisi, 1994; 31: 26-35.

18. Park YJ, Ryu H, Sun Han K, Kwon JH, Kim HK, Kang HC, Yoon JW, Cheon SH, Hyunjeong Shin H. Anger, anger expression, and suicidal ideation in Korean Adolescents. Archives of Psychiatric Nursing, 2010; 24(3): 168-177.

19. Rae G, Cohen S. Growing up with children. Canada: The Dryden Press, 1987.

20. Rikkli ER, Edwards JD. Effects of a three-year exercise program on Motor function and cognitive processing speed in older women. Research Quarterly for Exercise and Sport, 1991; 62: 61-67.

21. Robazza C, Bortoli L. Perceived impact of anger and anxiety on sporting performance in rugby players. Psychology of Sport and Exercise 2007; 8: 875-89.

22. Smith M, Hubbard JA, Laurenceau JP. Profiles of anger control in second-grade children: Examination of self-report, observational, and physiological components. Journal of Experimental Child Psychology, 2011; 110: 213-226.

23. Spielberger CD, Jacobs GA, Russell SF, Crane RJ. Assessment of anger: The state-trait anger scale. In J. N. Butcher, \& C. D. Spielberger (Eds.), Advances in personality assessment, Hillsdale NJ: Erlbaum, 1983: 159-187.

24. Spielberger CD. Manual for the State-Trait Anger Expression Inventory (STAXI). Odessa, FL: Psychological Assessment Resources, 1988.

25. Spielberger CD. State-trait anger expression inventory. Orlando, Florida, FL: Psychological Assesment Resources, 1991.

26. Thompson M, O'Neill-Grace C, Cohen LJ. Best Friends, Worst Enemies: Understanding the Social Lives of Children, Ballantine Book Published by The Random Hause Publishing Group, Ballantina Boks New York, 2002: 31-100.

27. Törestad B. What is anger provoking? A psychological study of perceived causes of anger. Aggressive Behavior, 1990; 16: 9-26.

28. Vecchio T, O'Lear DK. Effectiveness of anger treatments for specific anger problems: a meta-analytic review. Clinical Psychology Review. 2004; 24: 15-34.

29. Washington RL, Bernhardt DT, Gomez J, Johnson MD, Martin TJ, Rowland TW, et al. Ordanized sports for children and pre adolescent. Pediatrics, 2001; 107(6): 1459-1462.

30. Winnicott DW. Oyun ve Gerçeklik (Translate: Tuncay Birkan). İstanbul: Metis Yayınları, 1998.

31. Vitoratou S, Ntzoufras I, Smyrnis N, Scefanis NC. Factorial composition of the Aggression Questionnaire: a multi-sample study in Greek adults. Psychiatiy Res, 2009; 168: 32-39. 
